Kunstansprüchen in den Kunst-Diskurs eines technischen Verfahrens", p. I84). La "entrega posterior" de un diseńo a una fotografía confirma el potencial artístico de ese medio visual y, en consecuencia, surgen en los debates citados, desde luego, los criterios aprobados del arte tradicional: también en la fotografía se selecciona un motivo, se define un detalle, se cuida la iluminación; hasta en el proceso de revelado el fotógrafoartista manipula las sustancias y los tiempos para generar el efecto estético deseado. Al final de esos debates decimonónicos se rehabilita la fotografía - técnica, autopoiética-como arte que requiere la voluntad del creador, su capacidad de selección (criterio introducido por Nietzsche en MenschlichesAllzumenschliches durante estos años, p. I85) y su juicio estético firme — todo ello presente en la noción del "diseño entregado a posteriori” que describe, explica y justifica el acto creativo del fotógrafo.

Es importante mencionar, al final de esta revisión parcial del libro Entwerfen und Entwurf. Praxis und Theorie des künstlerischen Schaffensprozesses, que ese producto editorial se complementa con otro volumen sobre "los modelos de la producción artística" (Modelle künstlerischer Produktion, editado por Friedrich Weltzien y Amrei Volkmann, Berlín, Reimer, 2004); ambos documentan un proyecto interdisciplinario de investigación en la Universidad de las Artes de Berlín sobre la práctica y la teoría del proceso creativo artístico, un proyecto cuya fuerza intelectual radica en la innovación: en lugar del análisis tradicional de la obra de arte y su estética de recepción, ese modelo esbozado en el libro reseńado se presta para indagaciones en muchos campos y áreas culturales de nuestra disciplina.

\section{Suburbanismo y el arte de la memoria Sébastien Marot}

\author{
Barcelona, Gustavo Gili, 2006 \\ por \\ LETICIA SÁNCHEZ VIEYRA
}

Como parte de la colección Land \& Scape, la editorial Gustavo Gili presenta en 2006 un volumen del autor Sébastien Marot titulado Suburbanismo y el arte de la memoria, donde el autor, director y fundador de la revista Le Visiteur: Ville, Territoire, Paysage, Architecture hace valer su entrenamiento como crítico consolidado de arquitectura y paisaje. Manifiesta de este modo su desempeño profesional en diferentes países como Estados Unidos, Canadá y, por supuesto, su natal Francia, y la rica perspectiva que ello le brinda para abordar los temas tratados en el libro. Este volumen se apega al formato asignado a la colección por la editorial Gustavo Gili: se presentan los trabajos de teóricos, críticos y demás profesionales relacionados con el campo de la arquitectura, el paisaje y el urbanismo, en que se analizan y describen temas vinculados con la relación suelo-paisaje-arquitectura. Se trata de textos reducidos, combinados con una gran cantidad de imágenes de apoyo e ilustrativas que ayudan a los análisis y las descripciones planteados en los textos; por tanto, los números de la serie resultan ejemplares amenos y de fácil acceso, que sin embargo pueden leerse como libros teóricos especializados. En el que aquí se reseña, en particular, Marot aborda -a 


\section{DOI: http://dx.doi.org/10.22201/iie.18703062e.2010.97.2324}

partir del análisis del trabajo de varias personas con formaciones profesionales distintas $y$, por lo mismo, con enfoques diferentes - una perspectiva del urbanismo actual enfocada al estudio del suelo como portador de memoria en su representación física y cartográfica de suburbio, entendido éste como inevitable espacio divisorio entre lo rural y lo urbano, con énfasis en el suelo y la relación de éste con el hombre a través de la representación que de aquél se hace y de la memoria que de él se guarda. El libro se divide en cuatro partes y una coda, hiladas por fragmentos descriptivos del suelo con paisaje y las sensaciones que produce en el ser humano, expresadas en la pluma de Francesco de Colonna, en su obra El sueño de Polifilo, creada en la Italia del siglo Xv. Cada parte se dedica al análisis de un caso de estudio relacionado con un aspecto del suelo como superficie portadora de memorias diferentes, desde los puntos de vista y mediante los procesos de trabajo de cuatro personajes sobresalientes del siglo xx por su desarrollo intelectual y por el reconocimiento alcanzado en sus campos. Sus contribuciones se hilan para ejemplificar y sustentar los argumentos expuestos en el texto. Las cuatro referencias aprovechadas por el autor son el trabajo sobre la memoria de Frances Yates, historiadora inglesa; los escritos sobre El malestar en la cultura, del padre del psicoanálisis Sigmund Freud; el estudio de sitio y los recorridos realizados por Robert Smithson, artista estadounidense, $y$, finalmente, la perspectiva urbanística de intervención y regeneración del arquitecto suizo George Descombes, como ejemplo práctico ya realizado. El autor ha elegido estos cuatro ejemplos de ejercicio intelectual, metodología y casos de estudio -a los que bien podríamos llamar simplemente perspectivas - con el explícito fin de obtener representaciones heurísticas que ayuden más al autor que al lector a reafirmar el suburbanismo como concepto y a culminar el planteamiento del recurso de la memoria como medio y posibilidad concreta de acción del hombre habitante y creador en la intervención del suelo. En el marco de la serie Land \& Scape y probablemente debido a las preferencias estéticas del autor, de manera un poco forzada y a primera vista superficial, se hace hincapié en el paisaje, sobre todo en fragmentos del jardín como casos de análisis que se acomodan al tema abordado por cada uno de los autores elegidos por Marot, en particular en la primera mitad del libro. Pese a ello, siempre queda muy claro que la arquitectura, como forma de intervención del suelo — si se quiere ver así-, es un vínculo portador e instrumento de memoria, como el mismo Marot lo afirma.

A manera de capítulo introductorio, el autor expone los conceptos básicos de la problemática y plantea la solución que se desarrollará en el texto, a partir de la idea de que el urbanismo enfrenta en la actualidad el problema de que el territorio se hereda ya delimitado y configurado previamente y en el que hay emplazamientos que se transforman inevitablemente en el curso del tiempo. Entre las configuraciones del suelo y el territorio, Marot señala el espacio urbano y el rural, y, como factor de unión entre uno y otro, los suburbios. Sin embargo, el autor no menciona ni profundiza el estudio de los límites entre lo global y lo particular ni las fronteras que delimitan el suelo al volverlo territorio y las posibles mutaciones que experimentan. No obstante, señala al suburbio como envolvente, es decir como límite, siempre en función del crecimiento de la ciudad. Para el autor, el estudio urbano de los suburbios 


\section{DOI: http://dx.doi.org/10.22201/iie.18703062e.2010.97.2324}

permite un recuento y aprovechamiento de la memoria con que cargan estos sitios, así como un replanteamiento de la ciudad para realizar una obra arquitectónica, emprender una intervención urbana, adoptar una medida regeneradora y cuanta modalidad quepa en la disciplina del urbanismo, abordando el tema del emplazamiento y la ciudad desde una perspectiva que va del territorio circundante, es decir los suburbios, hacia el interior. Es pertinente mencionar que el autor considera el suburbio como límite, pues no habla del suelo rural como elemento portador de memoria por sí mismo y como posibilidad de materia para ejercer el urbanismo, y que su perspectiva incluye el tejido urbano nuclear y la mancha suburbana que lo rodea y a la vez lo configura en extensión. En esta parte de la introducción, el autor se refiere también a un movimiento de ruptura o contraposición con el urbanismo tradicional que pretende manifestarse con el nombre suburbanismo. También informa que se apoya en la aparente heurística de los cuatro trabajos citados en el texto, que por sí solos son estudios valiosos y tal vez heurísticos en su tema. No obstante, en el momento de hilarlos y utilizarlos para una argumentación de este tipo, pierden el impulso innovador que podrían dar al conocimiento. Sin embargo, es necesario reconocer la audacia de Marot al pretender plantear bases diferentes y una estructura nueva para abordar un problema ya existente en la actualidad, así como contribuir a mejorar la planeación de las intervenciones que pueden realizarse en la ciudad en el contexto de la disciplina urbanística actual.

Tras haber planteado la problemática del asunto y sus intenciones, el autor hace una referencia histórica fundamentando la importancia de la memoria del ser humano y las representaciones físicas que la evocan, entretejiendo la arquitectura como una forma de materialización de dicha memoria. Marot señala como ejemplo de ello los edificios clásicos, construidos a partir de la memoria colectiva de un paradigma representativo de ciertos elementos que daban el resultado formal de un edificio con tipología para una función determinada: templo, ágora y comercio, entre otros. Reviste gran interés, respecto al tema del texto, el otro enfoque presentado en este capítulo: la arquitectura en imagen, como herramienta mnemotécnica aprovechada por la humanidad desde los griegos, como recorrido virtual o mapa cognoscitivo en que se destina un espacio a cada concepto por memorizar. Para explicar esta parte, Marot se basa en el texto de Frances Yates sobre la memoria como arte y el desarrollo de esta habilidad en el ser humano. En este punto, Marot habla del lugar, concepto presente no sólo en éste, sino también en otros capítulos del texto, pero en esta ocasión se refiere a lugar desde el punto de vista de la memoria: lo que se recuerda es la formación de un lugar y, por tanto, dentro de la memoria el lugar está constituido por imágenes que pueden variar de la percepción real que se tiene al estar en contacto directo con él. La referencia a la obra de Yates es la apreciación del lugar como metáfora que es ocupado por lo que memorizamos. De la relación entre espacio físico-arquitectónico - emplazado en un sitio-, y lugar y percepción intelectual a manera de imágenes del espacio virtual —una vez más del lugar y la obra arquitectónica que representa la memoria - surgen nociones importantes para el planteamiento del suburbanismo propuesto por Marot. No obstante, los conceptos que expone, apoyado en el análisis del trabajo de Yates, no se hilan en los otros capítulos 


\section{DOI: http://dx.doi.org/10.22201/iie.18703062e.2010.97.2324}

del libro, donde podría haber continuidad y relación entre teoría y aplicación práctica dando un sustento teórico al proceder para el estudio de los suburbios como detonadores de un nuevo urbanismo, o la fundamentación del lugar como portador de memoria, que harían de esta conjunción una propuesta valiosa con grandes posibilidades. En cambio, se introduce el tema del jardín como ejemplo material de conjunción entre memoria y simbolismo y como sistema de disposición de la memoria al crear lugares, mostrando una mezcla de imágenes de diferentes mapas de memoria y jardines reales que complementan la explicación del jardín, pero que igualmente mueren al finalizar el capítulo para dar paso al análisis de la memoria psíquica y urbana que Marot presenta en la siguiente parte, basado en el libro El malestar en la cultura de Sigmund Freud.

Antes de empezar a analizar esa obra capital del padre del psicoanálisis dedicada a la conservación de sentimientos en lo psíquico e hilada al urbanismo mediante la metáfora — como la llama el mismo Freud- de Roma como ciudad histórica y ciudad psíquica, el autor compara los contextos de Yates, autora citada antes, y Freud, cuya obra corresponde a una época anterior. La relación entre ambos textos radica en la comparación siempre presente entre lo material y lo psíquico y la posibilidad de trasladar lo material al plano psíquico de la memoria. Marot pone el ejemplo que propone Freud, de Roma, y lo lleva al plano de transformación a partir de la ciudad física, analizando su composición como una "estratificación de trazas yuxtapuestas" que propone posteriormente

I. Sébastien Marot, Suburbanismo y el arte de la memoria, Barcelona, Gustavo Gili, 2006, p. 46. como metáfora para entender la estructura de la psique. Con ejemplos comparativos de esta índole, el autor desarrolla el segundo capítulo, tratando además de analizar la elección del ejemplo de Roma propuesto por Freud en El malestar en la cultura y utilizando parte de la argumentación para señalar la metáfora aplicable a la conservación del pasado de una ciudad, como modelo fiable y exacto de la estructura de la memoria psíquica, tratando de comparar más tarde el discurso psicoanalítico como fundamentación para el tratamiento del espacio urbano en el que exista una relación pasado-presente. Según Marot, la ciudad puede analizarse como un ser psíquico y como fundamento teórico. Para afirmarlo, se basa no sólo en su interpretación de Freud, sino también en el trabajo de Maurice Halbwachs, quien poco antes que Freud desarrolló un modelo de memoria donde propuso constituirla por marcos, como puntos de referencia que además diferencian el exterior tangible del interior psíquico. De esta manera, Marot hace hincapié en la intervención de la ciudad conservando la memoria colectiva que la forma, proponiendo la reconfiguración del espacio urbano, adaptándolo al presente y al futuro. Como conclusión del capítulo, el autor hace referencia superficial a los jardines como partes de la ciudad que permiten la evocación y refrendan la relación pasado-presente; sin embargo, el análisis se limita a esta breve observación que debiera ser hilo conductor del texto, pero que da la sensación de ser una presencia débil en la problemática principal.

La tercera parte del libro se enfoca a la relación del hombre con la experiencia y la memoria de la ciudad, al concepto de suburbanismo y al análisis de los suburbios como espacios de interés a partir de los re- 


\section{DOI: http://dx.doi.org/10.22201/iie.18703062e.2010.97.2324}

corridos e investigaciones realizados por el artista plástico Robert Smithson, quien en los años sesenta emprendió una serie de visitas a dos suburbios de Nueva York y elaboró los correspondientes registros gráficos. El autor se interesa en el proceso seguido por Smithson, quien trata de representar los emplazamientos y lo que sucede en ellos, como lo llama el propio Marot, identificando la sustancia psíquica y temporal, además de adoptar dos conceptos propuestos por Smithson, llamados site y non site, como parte de la teoría para hacer suburbanismo. El autor los liga al trabajo de Freud sobre Roma, al tratar de establecer una relación entre sitio e intelecto retomando también un ensayo de Smithson llamado "Vacaciones en Roma". El autor hace hincapié en la memoria urbana de esta ciudad, que permite olvidar la existencia geológica y prehistórica de la que también es resultado. En la segunda parte del capítulo aparece el término suburbio, que el autor define como territorio límbico o subciudad, y lo liga al término non site, que, de acuerdo con el propio Marot, acuña el mismo Smithson a partir de las visitas y el registro fotográfico que realiza de los suburbios americanos, aclarando que un non site no equivale al no lugar que podríamos interpretar; en cambio, tiene la particularidad de poder "expresar un lugar que no se le parece", ${ }^{2}$ haciéndolo un lugar con más lugares potenciales. Gran parte de este capítulo se resume en las imágenes que presenta Smithson de los suburbios, con la idea de reafirmar el estado de limbo en que los sitúa Marot. Se analizan también elementos aislados, como es el caso de un puente que liga al suburbio con la ciudad. Esta parte del

2. Marot, op. cit., p. 97. análisis recuerda un trabajo de Heidegger ${ }^{3}$ donde éste, de manera mucho más exacta y profunda, examina el puente como lugar construido por el hombre para unir dos extremos de suelo con toda la significación de la existencia y la relación psíquica con el lugar. Sin embargo, Marot analiza el trabajo de Smithson sin presentar mayores referencias, comparándolo también con un viaje hacia su pasado de reencuentro con su origen y sacando conclusiones sobre la periferia de las ciudades como posibilidad para intervenir en el nuevo urbanismo. Para terminar el capítulo, una vez más surge el tema del jardín, dentro de un ensayo de Smithson sobre Central Park, al que Marot se vuelve a referir como lugar de tiempo e historia, hablando además del trabajo de Smithson, quien reivindica el paisaje, según el autor, como una representación de la amnesia de la periferia suburbana.

El último análisis planteado en el libro es sobre el trabajo que realiza en Suiza y Holanda el arquitecto suizo Georges Descombes, quien logra crear y rehabilitar mediante una evocación del arte de la memoria. Como parte del análisis del proceder de Descombes, el autor explica la técnica de creación de un libro como análisis del sitio, en el que se plasma el desarrollo del paisaje presentando todos los elementos y personajes involucrados. En el texto se muestran una serie de imágenes con fotografías, mapas y bocetos — que emulan el libro de análisis citado anteriormente- sobre el trabajo de Descombes cuando rehabilita un parque en el suburbio de Lancy, Ginebra. Su trabajo, de acuerdo con Marot, consistió en intervenir el sitio y recuperarlo con el interés de ser el lugar de origen del arquitecto. El

3. Martin Heidegger, Construir, habitar, pensar, Barcelona, Serbal, I994. 


\section{DOI: http://dx.doi.org/10.22201/iie.18703062e.2010.97.2324}

autor plantea la intervención realizada por Descombes como un ejemplo inevitable de recuperación donde se utiliza el arte de la memoria, como sustento de esta hipótesis. En el libro se muestran varias fotografías de la intervención en diferentes etapas, incluida la recuperación de un túnel, donde se relaciona otra vez la presencia del puente, al igual que en el capítulo anterior, como un elemento psíquico. Para Marot la intervención permite leer la memoria del lugar y fomentarla, utilizar técnica y tectónica del suelo, basarse en la cartografía del sitio y argumentar el uso de antimonumentos a los que se refiere con la presencia de elementos guía en el discurso de la intervención. El autor usa generalmente conceptos como antimonumento y non site, cuando la representación física no corresponde con el paradigma que se debería tener de dichos elementos. Por ejemplo, en el caso del primero, se está refiriendo a elementos que el arquitecto utiliza como hitos dentro del discurso creador, que son al fin y al cabo monumentos en sí mismos por ser elementos representativos de la memoria que fungen como hitos dentro del sitio; sin embargo, al no corresponder con el paradigma que el autor tiene de un monumento, los llama de manera opuesta.

Al final del texto se agrega una coda, en la que Marot propone la extrapolación del suburbanismo y habla de dos tipos de memoria, la literal y la fenomenal, términos previamente abordados por Collin Rowe, Robert Slutzky y Gyorgy Kepes en sus diferentes obras. Además destaca el término transparencia - que utiliza en la memoria literal, al referirse al plano físicos-, la cual permite ver a través de una superficie explicando que en el suelo ésta es casi inexistente al no tenerse elementos naturales transparentes fuera de la presencia del agua. Sin embargo, la transparencia fenomenal debe lograrse permitiendo la recuperación de la memoria, siendo esto la idea central del texto, en el que se analizan una serie de casos que pueden extrapolarse y, así, contribuir, de acuerdo con el autor, al nuevo enfoque que debe tener el urbanismo de nuestros días, ya que "este siglo no pertenece a la extensión de las ciudades, sino a la profundización de territorios". ${ }^{4}$

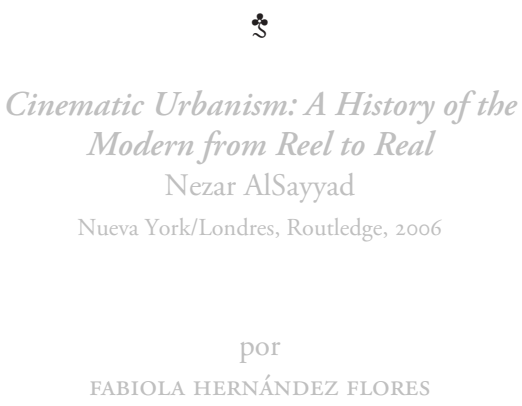

Nezar AlSayyad es profesor de arquitectura y urbanismo en la Universidad de California, Berkeley, donde imparte el seminario de diseño arquitectónico. En 1999 abrió el seminario Cinematic City con el objetivo de narrar la historia del urbanismo del siglo xx, utilizando el cine como marco de referencia. Cinematic Urbanism: A History of the Modern from Reel to Real surgió de las experiencias de AlSayyad como docente, coproductor de $A t$ home with Mother Earth, escritor y director de Virtual Cairo, ambos documentales para televisión, así como de las ideas sugeridas en los

Marot, op. cit., p. I49. 